\title{
Soluble urokinase plasminogen activator receptor in plasma of patients with inflammatory rheumatic disorders: increased concentrations in rheumatoid arthritis
}

\author{
Ole Slot, Nils Brünner, Henning Locht, Peter Oxholm, Ross W Stephens
}

\begin{abstract}
Objective-Urokinase type plasminogen activator (uPA) catalyses the formation of the proteolytic enzyme plasmin, which is involved in matrix degradation in the processes of tissue remodelling. Because of a surface bound UPA receptor (UPAR), expressed by some cell types (for example, macrophages, malignant cells and inflammatory activated synoviocytes), the action of UPA can be localised and intensified. uPAR seems to have a role in the mechanisms leading to invasive growth of malignant tissue and the rheumatoid pannus. uPAR may become cleaved at its cell surface anchor, thus forming a free soluble receptor (suPAR). suPAR is detectable in low but constant values in plasma of healthy people, while increased concentrations are found in patients with disseminated malignant disease, so that suPAR may be an indicator of invasive growth and tissue remodelling. suPAR concentrations in plasma have not previously been measured in rheumatic patients. A controlled cross sectional measurement was performed of suPAR in plasma of patients with various inflammatory rheumatic disorders with special ref-
\end{abstract} erence to rheumatoid arthritis (RA).

Methods-suPAR in plasma was measured by ELISA technique in patients with RA $(n=51)$ reactive arthritis ( $\operatorname{ReA})$ $(\mathbf{n}=23)$, primary Sjögren's syndrome (PSS) $(n=42)$ and sex and age matched healthy controls $(n=53)$.

Results-In the control group suPAR (median) was 0.91 (range $0.56-1.94) \mu g / 1$. Median suPAR value in RA was 1.47 (range 0.65-6.62) $\mu \mathrm{g} / 1$; in $\operatorname{ReA} 0.68 \mu \mathrm{g} / 1$ (range 0.52-1.48) and in PSS $1.12 \mu \mathrm{g} / 1$ (range 0.76-1.92); $p$ versus controls $<0.001$ in all patient groups. SuPAR values in RA were also significantly increased compared with $\operatorname{ReA}(\mathrm{p}<0.001)$ and PSS $(p=0.004)$ groups. suPAR in RA was positively correlated to $C$ reactive protein $(C R P)(p<0.01)$ and erythrocyte sedimentation rate $(p<0.05)$ and number of swollen joints $(p<0.05)$. The $\operatorname{ReA}$ group had the highest CRP values of all groups, but at the same time the lowest suPAR concentrations in plasma.

Conclusions-Increased suPAR concentrations were found in plasma in RA, and to a smaller extent also in PSS, but not in
ReA. In RA suPAR is related to disease activity. suPAR seems though not merely to be an acute phase reactant like CRP. Increased suPAR values might reflect erosive activity in RA.

(Ann Rheum Dis 1999;58:488-492)

The serine protease plasmin plays a central part in extravascular as well as intravascular fibrinolysis, and more generally in the extracellular matrix degradation that is an essential part of tissue remodelling. ${ }^{1}$ A crucial element in the regulation of these processes is the proteolytic activation of plasminogen to plasmin. Two types of plasminogen activators (PA) have been characterised: tissue type PA (tPA) and urokinase PA (uPA). The primary role of tPA is thought to be in fibrin dissolution and thrombolysis, while uPA is mainly involved in pericellular matrix degradation during tissue remodelling. ${ }^{2}{ }^{3}$ The effect of uPA is intensified and localised through binding to a specific cell bound receptor (UPAR), that is expressed on a variety of cell types, including neutrophils, monocytes/macrophages and malignant cells. ${ }^{3}$ Plasminogen activation is influenced by inflammation, and specifically the pro-inflammatory cytokines interleukin 1 and tumour necrosis factor $\alpha$ induce an upregulation of uPA and downregulation of tPA. ${ }^{45}$

Rheumatoid arthritis (RA) is characterised by chronic immune inflammation and invasive growth of synovial pannus tissue. Consistent with this, analysis of synovial tissue from RA and osteoarthritis patients, and normal synovial tissue have revealed higher uPA activity and markedly increased expression of UPAR in the RA synovial tissue, especially at the marginal zone between pannus and cartilage $^{6-12}$ uPA has been shown to induce bone resorption in vitro, and this effect was substantially increased when both uPA and uPAR were added. ${ }^{13}$ Increased uPA concentrations have also been found in RA synovial fluid, ${ }^{14-18}$ but not, however, in plasma, where normal or only slightly increased values of uPA were measured. ${ }^{17}{ }^{18}$

uPAR may be released from the cell surface by either cleavage of the glycolipid anchor by a phospholipase, or cleavage of the protein close to the anchor, thus forming a free soluble receptor (suPAR). ${ }^{19} 20$ suPAR is detectable in low, but fairly constant concentrations in plasma of healthy, normal people. ${ }^{19}{ }^{21}$ Increased plasma concentrations of suPAR have been 
Table 1 Characteristics of $R A$ patients

\begin{tabular}{ll}
\hline Number (female/male) & $51(39 / 12)$ \\
Age (y) mean (SD) (range) & $61.7(16.0)(24-83)$ \\
$\begin{array}{l}\text { Disease duration (months) mean } \\
\quad \text { (SD) (range) }\end{array}$ & $184(137)(6-550)$ \\
IgM-RF positive & $46 / 51(86 \%)$ \\
Erosions on radiography demonstated & $36(71 \%)$ \\
Tender joints (of 28) mean (SD) (range) & $7.7(7.0)(0-26)$ \\
Swollen joints (of 28) mean (SD) (range) & $5.5(5.6)(0-20)$ \\
Pain on 10 cm VAS mean (SD) (range) & $4.25(2.62)(0.2-9.7)$ \\
Patients global assesment of disease & \\
$\quad \begin{array}{l}\text { activity (10 cm VAS) mean (SD) } \\
\quad \text { (range) }\end{array}$ & $4.6(2.8)(0.1-9.6)$ \\
Assessor global assesment of disease & \\
$\quad$ activity (1-5 whole point scale) mean & \\
$\quad$ (SD) (range) & $2.5(1.1)(1-5)$
\end{tabular}

found in patients with advanced cancers of lung, breast and colon (reviewed in Behrendt and Stephen ${ }^{20}$ ). Increased suPAR concentrations in plasma seem to be a marker of invasive malignant growth ${ }^{3}$ and modalities of treatment influencing the uPA system are presently gaining increasing interest in oncology. ${ }^{20}$ Similarly, UPAR might play a pathophysiological part in inflammatory rheumatic diseases and increased concentrations of suPAR in plasma could be an easy accessible indicator of ongoing and extensive tissue degradation and remodelling.

To initially study the relations of suPAR in rheumatic disorders, we have in a cross sectional design measured suPAR in plasma of healthy controls and patients with various inflammatory rheumatic disorders with special reference to RA.

\section{Methods}

SUBJECTS

Three groups of patients and a control group were included in the study.

$R A$ group

This group consisted of 51 patients with various levels of inflammatory activity and no known malignancies; all fulfilling the ACR criteria for RA. ${ }^{22}$ Table 1 shows the characteristics of the RA patients. Twenty patients were receiving treatment with methotrexate (in eight patients in combination with low dose prednisolone $\leqslant 10 \mathrm{mg}$ daily), others were receiving treatment with sulfasalazine $(n=5)$, penicillamine $(n=3)$, parenteral gold $(n=2)$, hydroxychloroquine $(\mathrm{n}=3)$ or low dose corticosteroids alone $(n=6)$. Twelve patients received no disease modifying anti-rheumatic drugs (DMARDs). Nine RA patients received nonsteroidal anti-inflammatory drugs (NSAIDs). Records of radiographic investigations, performed as a part of routine clinical control, were used to evaluate the patients for the absence or presence of bone erosions.

\section{Reactive arthritis $(\operatorname{Re} A)$ group}

This group consisted of 23 patients ( 8 women and 15 men, aged $16-51$ (mean 32.0 ) years) with predominantly lower limb oligoarthritis usually after an enteric or urogenital infection. Disease duration ranged from 0.1 to 13 (mean 2.7) months. In five patients the triggering infection was caused by Yersinia enterocolitica or Salmonella sp, in two Chlamydia trachomatis, and one patient developed ReA after a streptococcal throat infection. In 15 cases the triggering infection could not be determined by either culture or serology, and the diagnosis of $\mathrm{ReA}$ was made when the patients fulfilled the criteria of monoarthritis or oligoarthritis in combination with at least one of the following: urethritis, dactylitis, sacroiliitis or conjunctivitis. One ReA patient was treated with sulfasalazine, one with methotrexate, 10 were taking NSAIDs and three had had local corticosteroid injections during the course of their disease.

\section{Primary Sjögren's syndrome (PSS) group}

This group consisted of 42 patients (40 women and two men, ages 27-88 (mean 62.8) years) all meeting the preliminary European Community diagnostic criteria ${ }^{23}$ as well as the Copenhagen diagnostic criteria ${ }^{24}$ for PSS. In addition to topical treatment for dry eyes and mouth, the patients were treated with hydroxychloroquine $(n=3)$ and low dose prednisolone $(\leqslant 10$ mg per day) $(n=3)$. Three patients received NSAIDs.

\section{The control group}

This group consisted of 53 healthy volunteers (39 women and 14 men, aged 22-82 (mean 55.6) years) matching the RA group with regard to age and sex.

\section{STUDY DESIGN}

Plasma and clinical parameters

Blood samples for suPAR measurement were obtained from participating subjects into EDTA tubes. Cells were removed after centrifugation at $3000 \mathrm{rpm}$ for 10 minutes within one hour, and the supernatants were stored at $-72^{\circ} \mathrm{C}$ until use. suPAR was analysed using a modification of the kinetic ELISA technique described previously. ${ }^{21}$ This method used the R2 monoclonal antibody (domain-3 specific) as capture antibody (coating $1.0 \mu \mathrm{g} / \mathrm{ml}$ ), and rabbit antihuman uPAR antibodies $(1.0 \mu \mathrm{g}$ $\mathrm{IgG} / \mathrm{ml}$ ) for detection of bound uPAR. A monoclonal antirabbit IgG antibody conjugate with alkaline phosphatase (Sigma, St Louis, MO; 1:2000 dilution) was used to enable continuous rate measurements.

On every ELISA plate a series of standards was included, which consisted of seven serial dilutions in triplicate of purified recombinant suPAR starting from $1 \mathrm{ng} / \mathrm{ml}$, then $0.5,0.25$, $0.125,0.0625,0.0313$ and $0.0156 \mathrm{ng} / \mathrm{ml}$. Also included on each plate were triplicate wells of a 1:10 dilution of a control citrate human plasma pool. The assay plates were measured in a Ceres 900 plate reader (Bio-Tek Instruments, Winooski, VT). The yellow colour development at $23^{\circ} \mathrm{C}$ was monitored automatically, with readings taken at $405 \mathrm{~nm}$ against an air blank every 10 minutes for 60 minutes. KinetiCalc II software was used to manage the data, calculate the rate of colour change for each well (linear regression analysis) and compute from the rates for the suPAR standards a 4 parameter fitted standard curve, from which the suPAR concentration of each plasma sample was calculated. 


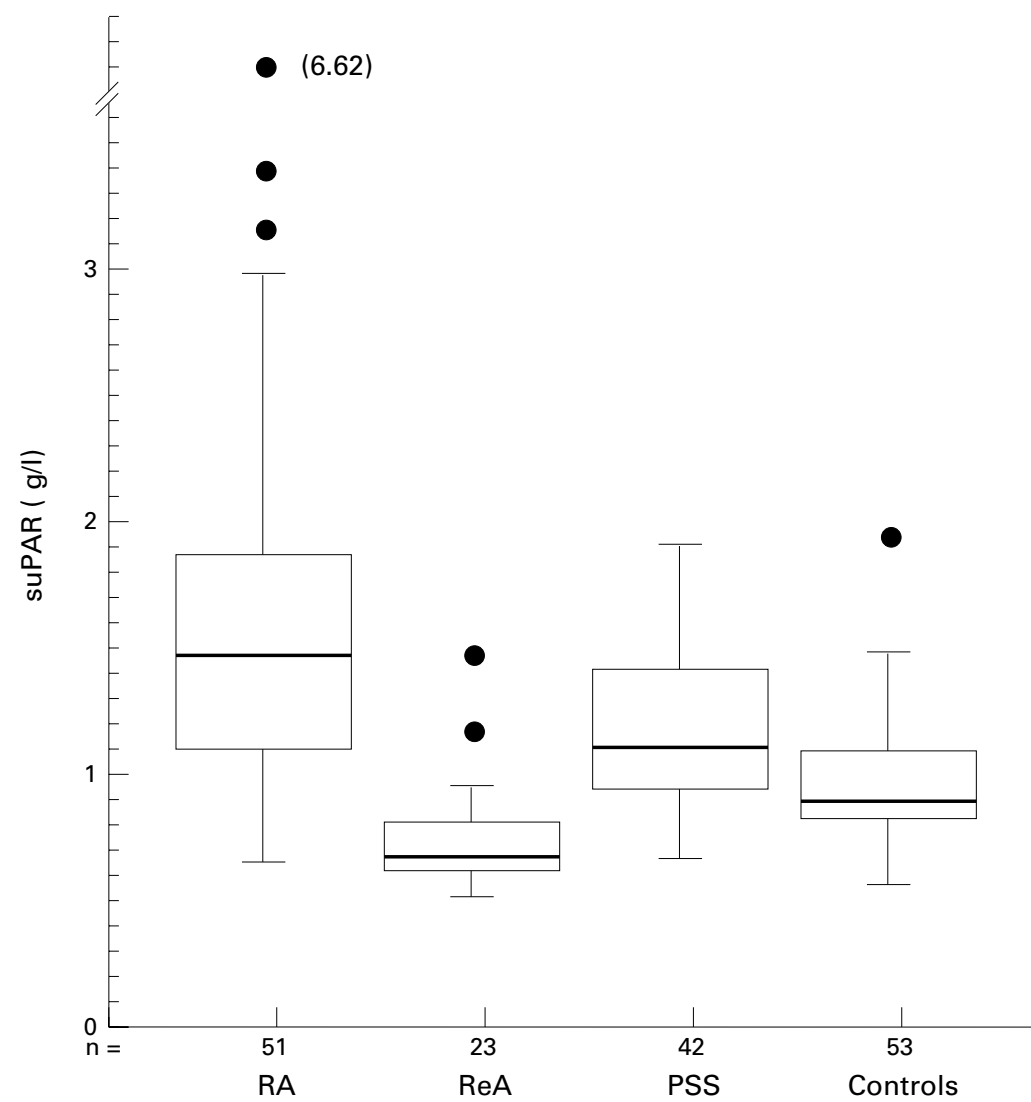

Figure 1 suPAR concentrations in different patient groups shown in box plots. Medians (heavy lines in boxes) and interquartile range are indicated as boxes. Whiskers indicates total range excluding outliers, which are shown separately. $R A$ : rheumatoid arthritis. ReA: reactive arthritis. PSS: primary Sjögren's syndrome.

$\mathrm{C}$ reactive protein $(\mathrm{CRP})$ was at inclusion measured by routine procedures. In the RA, ReA and control group erythrocyte sedimentation rate (ESR) was also measured in the morning by the Westergren method at inclusion.

Clinical evaluation of the patients included in the RA group measurement of swollen and tender joints on the 28 joint count model, patient reported pain and disease activity on a $10 \mathrm{~cm}$ visual analogue scale (VAS), and assessors global assesment of disease activity on a 1-5 whole point scale according to the EULAR recommandations for disease assessment in $\mathrm{RA}^{25}$

\section{STATISTICS}

The non-parametric Mann-Whitney test was used for the differences between groups, and the non-parametric Spearman test was used for correlations. The level of statistical significance was chosen as $\mathrm{p}<0.05$. SPSS software was used to construct a database, and to make the statistical calculations and graphic.

Table 2 Median CRP ( $\mathrm{mg} / \mathrm{l}$, normal range <5.0-9.9 $\mathrm{mg} / \mathrm{l})$, ESR ( $\mathrm{mm} 1 \mathrm{st} \mathrm{h}$ ) and suPAR $(\mu g / l)$ values in the patient groups and control group. Statistical probability of the differences in suPAR compared with the study control group and the RA group respectively are shown

\begin{tabular}{lllll}
\hline & $R A$ & $R e A$ & PSS & Control \\
\hline CRP $(\mathrm{mg} / \mathrm{l})$ & $9.0(<5.0->91.3)$ & $34.0(<5.0-122.3)$ & $<5.0(<5.0-59.6)$ & $<5.0(<5.0-15.6)$ \\
ESR (mm 1st h) & $30(4-100)$ & $40(6-104)$ & - & $4(1-38)$ \\
SuPAR $(\mu \mathrm{g} / 1)$ & $1.47(0.65-6.62)$ & $0.68(0.52-1.48)$ & $1.12(0.67-1.92)$ & $0.91(0.56-1.94)$ \\
$\mathrm{p} v$ Controls & $\mathrm{p}<0.001$ & $\mathrm{p}<0.001$ & $\mathrm{p}<0.001$ & - \\
$\mathrm{p} v$ RA & - & $\mathrm{p}<0.001$ & $\mathrm{p}=0.004$ & $\mathrm{p}<0.001$ \\
\hline
\end{tabular}

ETHICS

The study was approved by the local scientific ethical committee (KA 97171).

Results

The results of the study appear in figure 1 and table 2.

suPAR concentrations in the control group were distributed in a fairly narrow range. A positive correlation to age was shown $(\rho=0.43$, $\mathrm{p}<0.01$ ). No difference between plasma suPAR concentrations in women and men was found.

In the RA group significantly increased suPAR concentrations were found compared with the control group: median (range) 1.47 (0.65-6.62) $\mu \mathrm{g} / 1 v 0.91(0.56-1.94) \mu \mathrm{g} / \mathrm{l}(\mathrm{p}<$ $0.001)$. suPAR in RA was also increased compared with the other patient groups: RA $v$ $\operatorname{ReA}: 1.47$ (0.65-6.62) $\mu \mathrm{g} / 1 v 0.68$ (0.52-1.48) $(\mathrm{p}<0.001) ; \mathrm{RA} v$ PSS:1.47 (0.65-6.62) $\mu \mathrm{g} / \mathrm{l} v$ $1.12(0.67-1.92) \mu \mathrm{g} / 1(\mathrm{p}=0.004)$.

The RA group was for analytical purposes divided into two groups with suPAR values over and below the median value. No differences between the group of RA patients with high $\operatorname{suPAR}(>1.47 \mu \mathrm{g} / \mathrm{l}, \mathrm{n}=25$ ) compared with the group of RA patients with low suPAR $(\leqslant 1.47 \mu \mathrm{g} / \mathrm{l}, \mathrm{n}=26)$ could be demonstrated with respect to seropositivity, erosions on radiography or medical treatment. The patients with high suPAR had shorter disease duration (mean: $127 v 160$ months), but the difference did not reach statistical significance.

suPAR concentrations in RA were significantly positively correlated to CRP $(\rho=0.44$; $p<0.01)$, ESR $(\rho=0.35 ; p<0.05)$, number of swollen joints $(\rho=0.29 ; p<0.05)$ and age $(\rho=0.28 ; p<0.05)$.

In the PSS group significantly increased suPAR concentrations were found compared with the study controls: $1.12(0.67-1.92) \mu \mathrm{g} / 1 v$ $0.91(0.56-1.94) \mu \mathrm{g} / 1 \quad(\mathrm{p}<0.001)$, while the patients in the ReA group had significantly lower suPAR concentrations than the study controls $0.68(0.52-1.48) \mu \mathrm{g} / 1 v 0.91(0.56-$ $1.94) \mu \mathrm{g} / 1(\mathrm{p}<0.001)$. In the $\operatorname{Re} A$ group no correlation was found between suPAR and CRP or ESR, while a correlation was found between suPAR and CRP in the PSS group $(\rho=0.36$, $\mathrm{p}<0.05)$.

In one RA patient extremely high suPAR $(6.62 \mu \mathrm{g} / \mathrm{l})$ was measured. This patient had inflammatory active RA, and developed during the period of this investigation erosive bone changes on radiographic investigation. The patient did not in any other way differ from other inflammatory active RA patients.

\section{Discussion}

This study is to our knowledge the first report of suPAR concentrations in plasma of patients with inflammatory rheumatic diseases. We were able to demonstrate a significant increase in suPAR concentrations in plasma of a group of RA patients, most of them with longstanding disease and clinically presenting with only mild to moderate disease activity, and many receiving treatment with DMARDs.

The release of suPAR from the surface of cells is believed to occur through either the 
action of phospholipases on the glycolipid anchor of UPAR, or the cleavage of UPAR protein by proteases. ${ }^{20}$ The release of UPAR could be part of a counteracting self regulating mechanism attenuating localised plaminogen activation. The soluble receptor has the ability to bind $\mathrm{uPA}$, but the physiological function of the free receptor is unknown. Nevertheless, suPAR concentrations in healthy persons are fairly constant, which might indicate a physiological regulation of suPAR concentrations.

A positive correlation of suPAR to age was found in RA, but this was not different to the observations made in the control group. suPAR concentrations in the RA patients correlated with the indices of disease activity: CRP, ESR and number of swollen joints. However, suPAR appeared not to be merely an acute phase reactant, because while the ReA patient group had the highest CRP concentrations, this group was found to have very low suPAR concentrations.

Seventy one per cent of our RA patients were at some time during their routine follow up shown to have bony erosions. The fact that we were unable to demonstrate any relation between suPAR concentrations and radiographic confirmed erosions, may be attributable to the study design, where erosions may not have been observed yet, as radiographic investigations were not done systematically at inclusion. But it may also reflect that suPAR levels are correlated to ongoing disease activity, while bone damage is the result of previous and longstanding disease activity.

Follow up studies including RA patients with early arthritis may help to clarify the possible relation between uPA activity, and in particular suPAR concentrations, and the tendency to evolve destructive tissue damage. Therapeutic inhibition of the uPA system to counteract invasive growth of pannus tissue might in the future represent a new treatment modality for $\mathrm{RA}$, as it has already been suggested. ${ }^{26}{ }^{27}$ On the other hand, one action of the fibrinolytic system is the removal of fibrin from the synovial space, which seems to have a beneficial effect on the arthritis, ${ }^{2829}$ and the net effect of modulating the uPA system is therefore at present difficult to predict.

The RA group also showed increased suPAR concentrations compared with other groups of patients with inflammatory rheumatic disorders. This might indicate the differences in capacity of destructive, erosive growth of inflammatory tissue between RA and the other disorders. On the other hand the PSS group showed a slight, but significant increase in suPAR as compared with healthy controls, suggesting that the uPA system in this immunoinflammatory disorder may also play a pathogenic part.

That the ReA group had lower suPAR concentrations than our control group might at least partly be explained by differences in age distribution of the two groups.

It is not possible from this study to evaluate the effects of DMARDS and corticosteroids on the uPA system, as patients with active disease and presumably increased uPA activity, also are more likely to be receiving treatment with these drugs. Our study included too few patients with short disease duration to evaluate the suPAR concentrations in early arthritis before treatment with DMARDs is started.

In conclusion, we found increased concentrations of suPAR in RA with correlation to disease activity. These results in our opinion are interesting enough to call upon further prospective studies of suPAR concentrations in $\mathrm{RA}$ to evaluate whether suPAR concentrations in plasma constitute a valuable early marker of erosive, destructive arthritis, and whether in the future treatment entailing inhibition of the uPA system could become a therapeutic option.

Else Borresen, laboratory technician, Department of Clinical Chemistry, Copenhagen County Hospital Gentofte and Maria J A G Hamers, research assistant, Finsen Laboratory, Copenhagen University Hospital are cordially thanked for their gen University Hospit

1 Rømer J, Bugge TH, Pyke C, Lund L, Flick MJ, Degen J L, et al. Impaired wound healing in mice with a disrupted plasminogen gene. Nat Med 1996;2:287-92.

2 Vassalli J-D, Sappino A-P, Belin D. The plasminogen Vassalli J-D, Sappino A-P, Belin D. The plasminogen

activator/plasmin system. J Clin Invest 1991;88:1067-72. The urokinase receptor. Protein structure and role in plasminogen activation and cancer invasion. Fibrinolysis 1994;8 (suppl 1):189-203.

4 Campbell IK, Piccoli DS, Roberts MJ, Muirden KD, Hamilton JA. Effects of tumor necrosis factor $\alpha$ and $\beta$ on resorption of human articular cartilage and production of plasminogen activator by human articular chondrocytes. Arthritis Rheum 1990;33:542-52.

5 Brommer EJP, Dooijewaard G, Dijkmans BAC, Breedveld FC. Depression of tissue-type plasminogen activator and enhancement of urokinase-type plasminogen activator as an expression of local inflammation. Thromb Haemost 1992;68:180-4.

6 Kirchheimer JC, Remold HG, Wanivenhaus A, Binder BR. Increased proteolytic activity on the surface of monocytes from patients with rheumatoid arthritis. Arthritis Rheum 1991;34:1430-3.

7 Zacharski LR, Brown EF, Memoli VA, Kisiel W, Kudryk BJ, Rousseau SM, et al. Pathways of coagulation activation in situ in rheumatoid synovial tissue. Clin Immunol Immunopathol 1992;63:155-62.

8 Belcher C, Fawthrop F, Bunning R, Doherty M. Plasminogen activators and their inhibitors in synovial fluids from normal, osteoarthritis, and rheumatoid arthritis knees. Ann Rheum Dis 1996;55:230-6.

9 Ronday HK, Smits HH, van Muijen GNP, Pruszczynski MSM, Dolhain RJEM, van Langelaan EJ, et al. Difference in expression of the plasminogen activation system in synovial tissue of patients with rheumatoid arthritis and vial tissue of patients with rheumatoid arthri

10 Busso N, Péclat V, So A, Sappino A-P. Plasminogen activation in synovial tissues: Difference between normal, tion in synovial tissues: Difference between normal, osteoarthritis, and rhe
Dis 1997;56:550-7.

11 Szekanecs Z, Haines GK, Koch AE. Differential expression of the urokinase receptor (CD87) in arthritic and normal synovial tissues. J Clin Pathol 1997;50:314-19.

12 Cerinic MM, Generini S, Partsch G, Pignone A, Dini G Kontinen YT, et al. Synoviocytes from osteoarthritis and rheumatoid arthritis produce plasminogen activators and plasminogen activator inhibitor-1 and display u-PA receptors on their surface. Life Sci 1998;63:441-53.

13 Ronday HK, Smits HH, Quax PHA, van der Pluijm G, Löwik CWGM, Breedveld FC, et al. Bone matrix degradation by the plasminogen activation system, possible mechanism of bone destruction in arthritis. Br J Rheumatol 1997; nism of 9 -15.

14 Mochan E, Uhl J. Elevations of synovial fluid plasminogen activator in patients with rheumatoid arthritis. J Rheumato $1984 ; 11: 123-8$

15 Kikuchi H, Tanaka S, Matsuo O. Plasminogen activator in synovial fluid from patients with rheumatoid arthritis. J Rheumatol 1987;14:439-45.

16 Saxne T, Lecander I, Geborek P. Plasminogen activators and plasminogen activator inhibitors in synovial fluid. Difference between inflammatory joint disorders and osteoarthritis. J Rheumatol 1993;20:91-6.

17 Kummer JA, Abbink JJ, de Boer J-P, Roem D, Nieuwenhuys EJ, Kamp AM, et al. Analysis of intraarticular fibrinolytic pathways in patients with inflammatory and noninflammatory joint diseases. Arthritis Rheum 1992;35:884-93.

18 Brommer EJP, Dooijewaard G, Dijkmans BAC, Breedveld FC. Plasminogen activators in synovial fluid and plasma FC. Plasminogen activators in synovial fluid and plasma
from patients with arthritis. Ann Rheum Dis 1992;51: from patic 8 .

19 Rønne E, Pappot H, Grøndahl-Hansen J, Høyer-Hansen G, Plesner T, Hansen NE, et al. The receptor for urokinase plasminogen activator is present in plasma from healthy 
donors and elevated in patients with paroxymal nocturnal haemoglobinuria. Br J Haematol 1995;89:576-81.

20 Behrendt N, Stephens RW. The urokinase receptor. Fibrinolysis and Proteolysis 1998;12:191-204.

21 Stephens RW, Pedersen AN, Nielsen HJ, Hamers MJAG, Høyer-Hansen G, Rønne E, et al. ELISA determination of soluble urokinase receptor in blood from healthy donors and cancer patients. Clin Chem 1997;43:1876-84.

22 Arnett FC, Edworthy SM, Bloch DA, McShane DJ, Fries JF, Cooper NS, et al. The American Rheumatism Association 1987 revised criteria for the classification of rheumatoid arthritis. Arthritis Rheum 1988;31:315-24.

23 Vitali C, Bombardieri S, Moutsopoulos HM, Balestrieri G, Bencivelli W, Berstein RM, et al. Preliminary criteria for the Bencivelli W, Berstein RM, et al. Preliminary criteria for the
classification of Sjögren's syndrome. Arthritis Rheum 1993;36:340-7.

24 Manthorpe R, Oxholm P, Prause JU, Schiödt M. The Copenhagen criteria for Sjögrens syndrome. Scand J Rheumatol 1986;S61:22-5
25 Scott DL, van Reil PL, van der Heide D, Benke AS. Assessing disease activity in rheumatoid arthritis. In: The EULAR handbook of standard methods. London: EULAR, 1993.

26 Fibbi G, Pucci M, Serni U, Cerinic MM, Del Rosso M. Antisense targeting of the urokinase receptor blocks urokinase-dependent proliferation, chemoinvasion, and chemotaxis of human synovial cells and chondrocytes in

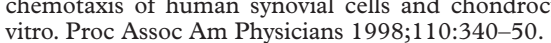

27 Del Rosso M, Fibbi G, Pucci M, Cerinic MM. Antisense oligonucleotides against the urokinase receptor: a therapeutic strategy for the control of cell invasion in rheumatoid arthritis and cancer. Clin Exp Rheumatol 1998;16:389-93.

28 Busso N, So A. Urokinase in rheumatoid arthritis: causal or coincidal? Ann Rheum Dis 1997;56:705-6.

29 Busso N, Peclat V, Van Ness K, Kolodziesczyk E, Degen J, Bugge $\mathrm{T}$, et al. Exacerbation of antigen-induced arthritis in urokinase-deficient mice. J Clin Invest 1998;102:41-50. 